\title{
Must doctors save their patients?
}

\author{
John Harris Department of Education, University of Manchester
}

\section{Author's abstract}

\begin{abstract}
Do doctors and other medical staff have an obligation to treat those who need their help? This paper assumes no legal or contractual obligations but attempts to discover whether there is any general moral obligation to treat those in need. In particular the questions of whether or not the obligation that falls on medical staff is different from that of others and of whether doctors are more blameworthy than others if they fail to treat patients are examined. Finally we look at the question of the burden of this obligation and at the responsibility of society to mitigate its hardships.
\end{abstract}

'There is a question here which needs discussion: whether, when and why a doctor has an obligation to do anything for someone? Can't a doctor sometimes say: "I do not want to treat this patient, I actually don't want him as a patient of mine?" Can he sometimes, or can he never say the following?: "I do not want to prolong this person's life by taking medical measures to do so. I am not saying it is better not to; I would say nothing against another practitioner who might want to. But I don't want to. And I don't have to".'

This question of G E M Anscombe's (1) she rightly identifies as 'a deep and important question of medical ethics', and it is this question, or rather these questions that I wish to attempt to answer here.

A proper answer to them may well prove to be an answer to the very general and much larger question: what is our obligation to care for one another? Or, scarcely narrower, what is society's obligation to care for and protect its citizens? With these possibilities in mind we will try to maintain a sharp focus and talk for the most part of doctors, nurses and other medical staff (2). Here Professor Anscombe identifies two questions: the first is the question of whether or not there is any obligation to do something in the way of medical treatment for others and the second is whether there can be any obligation to do something 'medical' to prolong the life of another person.

\section{Key words}

Medical; treatment; obligation; doctor's duty; doctor-patient relationship; medical ethics.

\section{What is 'medical' treatment?}

Before looking at these questions, however, we must ask what is implied by the use of the term 'medical' to qualify what is or is not done for other people. Much of the 'treatment' offered by doctors is simply advice as to diet, rest, exercise, cleanliness and so on or, it may even be general advice about the probable effects of a particular lifestyle. This advice of course, may well prolong life. Where more palpable treatment is offered, say in the form of 'drugs', the question of what is specially 'medical' about the treatment is just as problematic. The drugs may be proven therapies, appropriately prescribed, they may or may not help. They may be placebos, given to the sick in the absence of anything proved to be more efficacious, or they may be given to hypochondriacs; either group may consequently recover or they may not. The treatment may be major surgery or it may be 'nursing care only'. Because of the wide variety of activities or absences of activity which may be described as 'treatment' and because of the wild variation in probable, expected or hoped for, actual or imagined success, indeed because of the great difficulty of defining 'success', it is difficult in the extreme to define medical treatment in terms of any of these. I shall in consequence take 'medical treatment' to refer to anything done or deliberately left undone by doctors or other medical staff, or at their direction, to or for people who either offer themselves for such treatment or who are in such a state that it seems sensible to call on doctors for help or to or for people who are presented perforce for such help.

\section{Postponing death}

So, having been called on for help, does a doctor's obligation (whatever that obligation turns out to be) differ in cases where her judgment is that such help as can be given ( $s ;$ - omfort, or relief of pain or setting a broken limb, or uAvice, or simply diagnosis) will not (probably) prolong life, from those cases where it (probably) will? Clearly, life-saving, or more accurately deathpostponing actions, are of the highest moral importance. And they are so for precisely the same reasons that death-dealing or murderous ones are, generally, the most serious of crimes. This is not, of course, to say that many of the things that we do for one another 
which are not death-postponing are not,morally speaking, very important indeed. But while the prolongation of life is not necessarily or always more important than that of giving the other sorts of help that may be required, it is always of the first importance, and except in very rare cases, the saving of life, or the attempt so to do, is the first and most urgent requirement. So while we may want to rank-order the multifarious varieties of care and other treatment that doctors may perform, there is no need to grade the importance of saving life.

There may then be a fairly systematic difference in our judgments about the importance of medical treatment which does not save or prolong life and that which does; and this may well influence our judgments about the force of whatever obligation there may be to give treatment, or even our judgment as to whether or not there is any such obligation at all. To avoid this further complication of our investigation we will concentrate on those cases which are always of the first importance and so on Professor Anscombe's second question: Is there an obligation to prolong life by taking medical measures so to do?

\section{Refusing patients and refusing treatment}

Can a doctor say of a dying patient 'I do not want to treat this patient, I actually don't want him as a patient of mine?' There are two possibilities here: i) that a doctor refuses to accept someone as her patient, ii) that she refuses to treat one of her patients. How different are these and do they indicate different possible obligations on the part of the doctor?

Superficially the difference between these two possibilities is that in the first instance a doctor refuses to take responsibility for someone, refuses to ascertain whether or not he or she needs her help and whether or not she can or cannot do anything for that person. In the second instance she takes, or somehow has responsibility for the patient, and refuses to discharge that responsibility. In a society which has many doctors (even if the 'many' are in fact a scarcity) refusal to accept someone as a patient may just mean that some other doctor will (will have to?) accept him. Similarly, refusal to treat will just mean that some other doctor will (will have to?) treat him. There may of course be a long line of such doctors but we must concentrate on the doctor at the end of the line, or on the doctor who, for a particular patient (for example, because that patient will not survive being moved along to the next practitioner) is the doctor at the end of the line. The doctors up the line have passed on the responsibility for the patient, but they have also passed on whatever force there is in the obligation of doctors to treat the sick. This force can only be fully felt at the point where a person's fate hangs upon whether or not he gets the treatment he needs here and now from this doctor.

Now, if you are that doctor the consequences for the patient of your saying ' $I$ do not want to treat this patient' are the same as saying 'I . . . don't want him as a patient of mine'. Of course, you, the doctor, may not know that they are the same, indeed, if you refuse to take on the patient you may effectively shield yourself from any knowledge of his condition let alone of his fate. This may or may not affect moral assessments of your character and we will return to this point, but for now it is important to stress that this makes no difference to the patient. In both cases the patient will die and he will die because you refused to treat him. This may be a controversial conclusion but I think it is an inescapable one, and it is worth taking time out to indicate why this is so. The argument is a large one but its force can be shown fairly briefly (3).

\section{Decisions can be decisive}

Doctors' decisions do make a difference to what happens to their patients, and in this regard I take it that decisions not to do things, to take no action, are as important and crucial as various sorts of intervention. The day-to-day care of most patients will involve innumerable decisions to do and not to do various things and each will have its effect on the course of an illness and on the chances of recovery. More dramatically, consider the case of a known diabetic admitted to the casualty department of a hospital in a hypoglycaemic coma. If the casualty officer suspecting this condition failed to, or refrained from, taking the blood sugar level of the patient and so also failed to give glucose in an appropriate form and the patient died there would be no difficulty in recognising that the death was a consequence of that decision not to treat. Or, if a patient was admitted to hospital having obviously lost vast quantities of blood and a decision was taken not to replace this with an appropriate saline or other solution pending blood transfusion, and the patient died, there would again be no problem in recognising that the death resulted from the decision not to take appropriate measures to make good the loss. In either case the first question that any investigation into the causes of the patient's death would require to be answered is: why was he or she left untreated?

In these examples, of course, the patients have been admitted to hospital and so in a sense the hospital has taken responsibility for them, has accepted that there is an obligation to treat them. Is it not therefore the breach of this obligation that makes it the case that if the patients die their deaths will be a result of the failure to treat? Moreover, might it not be argued that this case cannot be used in illustration of the causal connection between a decision not to treat and its 'consequences' because to do so would beg the question of whether there is any such obligation and this is precisely the question we are investigating? This objection is not well founded for we can clearly see the causal connection between failure to treat and death quite independently of the existence of any obligation to treat.

Firstly, suppose that as a result of our deliberations here we firmly conclude that doctors have in fact no moral or other obligation to treat patients. Our reaching this conclusion would not prevent us from seeing that the diabetic and haemorrhaging patients we have 
imagined died because they were not given the treatment that would keep them alive. We would understand very well that this was the reason for their deaths but accept, presumably, that it is not morally wrong to cause death in circumstances like these. How plausible a judgment this might be is, of course, a question to which we will shortly return. A further and perhaps clearer illustration is the case of so called 'selective treatment' where doctors give instructions that 'nursing care only' be given to, inter alia, severely handicapped children. This involves among many other restrictions on treatment, the decision not to give antibiotics to cure any infection the child may contract. If the child becomes infected it is well understood to be much more likely to die if antibiotics are withheld, and our understanding of the connexion between the doctor's decision and the death of the child is not dependent on any judgment about this involving a breach of any duty to care: because those involved, who well appreciate the consequences of their decisions, judge these decisions to be fully consistent with their duty to treat their patients caringly, properly and professionally.

We cannot then avoid the conclusion that if a doctor refuses to treat a patient, who in the circumstances only that doctor can save, then the death will be a consequence of that refusal. But is the doctor morally obliged not to refuse? Again, we are interested here in the question of what moral obligations there are which derive purely from one party being a doctor and the other needing her help. Many doctors would have all sorts of contractual obligations in such circumstances and, irrespective of the legal status of these, there will also perhaps be moral obligations to honour contracts. But our interest is concentrated entirely on the question of moral obligation per se.

\section{What is a doctor's business?}

It is sometimes said that saving life is always a doctor's business, that is what she is trained for, it is her vocation. This, while perhaps uncontroversial, is too weak a consideration upon which to found moral obligation. For playing cricket is always a cricketer's business (if indeed it can be so described), it is what he is trained for, it is his vocation. But that does not mean that he is obliged to play in every match, or every time someone turns up wishing to see him play. Perhaps this analogy misses an important point, that medicine is special, and its specialness consists simply in its role in saving life and in healing or caring for health and in the special priority we give to all these things.

First and of course, we do attach special importance to prolonging life and to recovering from illness and injury and to relief of pain. We attach the same importance to the avoidance of subjection to involuntary and substantial risks to life and health and to the risk of being subjected to pain. However, it would be odd to think that there was some special category of person whose unique and first responsibility it was to refrain from killing or injuring us or from subjecting us to sub- stantial risk of death or injury or pain. No one at all should subject us to these or the risk of them. Similarly, and for the same reasons, anyone who can should save or help save our lives and preserve our health.

But wouldn't a doctor be specially blameworthy if, knowing how incompetent a physician she was, she allowed a patient to die rather than risk the disgrace of muffing a simple life-saving procedure? She would, moreover, be more blameworthy than would a lay bystander who happened to know the appropriate procedure but was unwilling to risk employing it; just as an incompetent lifeguard would be more to blame for failing to rescue a drowning man than would another competent swimmer who also witnessed the drowning. It is important here not to confuse the moral assessment of character with the moral assessment of actions. Take the case of a completely innocent man. No one at all should murder him and everyone's obligation not to do so is equally strong. However, if his son were to murder him we might think the son more wicked than we would a murderous stranger. This does not mean, however, that his son was under a stronger moral obligation not to murder him than was the stranger, nor that his murder was more to be deplored in the one case than in the other. In each case the murder was equally bad and the obligation to refrain from it equally strong - only our moral assessment of the character of the murderer differs. Similarly, we may think the doctor and the lifeguard more to blame for their moral cowardice than were the others, but not that their obligation was stronger nor that the victim was more wronged by one of them than by any other.

\section{Two faces of the obligation to treat}

There are then two sorts of moral obligation here, or rather, as I see it, two ways of thinking about one and the same obligation. I won't enquire where this obligation comes from because in one or other of its forms it is almost universally recognised. For our present purposes we will have gone a long way towards making clear the nature of the moral obligations of medical staff if we can show that they fall under one or other aspect of this more general and widely recognised duty.

According to the first way of thinking about this duty it is part of our duty to refrain from killing or injuring others. Because, as we have seen, where we decide not to treat someone knowing that he will die as a consequence, or decide not to rescue someone knowing that she will die as a consequence, then in both cases we are responsible for their deaths (4).

The second way of thinking of this obligation is to see it as part of what it is to value human life. An irreplaceable part of what it is to value life must be a belief that it is better that people live rather than die, and die later rather than earlier and also that their lives be as unimpaired by ill-health, injury, suffering and so on as it is possible to make them. Moreover, it must also be part of what it is to value human life to believe that it remains better that death should be postponed and life chances made as good as they can be for so long as the 
individual's life remains valuable to that individual. These remarks are not, or course, intended to provide anything like an exhaustive account of what it is to value human life. They do none the less provide the irreplaceable core of such an account, so that no one could plausibly claim to value human life, or whatever counts as human life when any exceptions and qualifications have been made, unless she remained committed to postponing death and ameliorating the quality of life for so long as the person in question found life valuable (5).

\section{Rescue is everyone's business}

On either account of our obligations to others, in addition to refraining from murder and other forms of bodily harm, we should also rescue others so that they do not lose or otherwise involuntarily impair their valuable lives. We believe for example that we should rescue trapped miners and other victims of accidents, or those shipwrecked, or the victims of hijackers or other hostage-takers; and not least, those who can only be rescued by medical care. Some of these rescues can be performed by anyone who is on hand, others require all sorts of expertise from that of pot-holers, sailors, miners, engineers, firemen and so on, to specialised military personnel and those with medical skills. Very often, those of us who lack these skills can best help, and thus discharge our obligation to those at risk, by keeping well out of the way. All of this is perhaps obvious enough but it helps us to see two important features of the obligation of medical staff. The first is that there is nothing special about their obligation in particular. Just as there is no special category of person whose unique and first obligation is to refrain from inflicting death, injury or suffering on the rest of us, so there is no one, morally speaking, (6) who is specially required to undertake rescues. Anyone at all who either values human life or who believes that no one should behave in ways that will needlessly harm others, must help if he can, or must help unless there are good reasons why he should or need not; and these we will look at in a moment.

Although I have said there was nothing special about the obligations of medical staff this was perhaps hasty: what's special about them is simply that their special skills enable them to rescue others from a particularly pervasive and heterogeneous group of dangers. But we should be clear that the reasons why they should do so are the same as the reasons why any of us should rescue any others of us if we can, or the reasons why we should refrain from decisions which we know will result in harm to others. Of course, it may well be that medical staff have acquired what skills they have expressly for the purpose of effecting rescues and have thus in a way 'undertaken' to carry out the job. But we are here interested in the question of what general moral grounds there are for thinking a doctor is obliged to continue to do that job when perhaps she has withdrawn or feels like withdrawing or cancelling her undertaking, or disputes its nature or even its exis- tence, in circumstances in which she is the last doctor, the only one who can help.

\section{Saving life is a moral issue}

The second important feature of the obligations of medical staff made clearer by seeing those obligations as the same as those which fall on the rest of us, is that medical staff have no special prerogatives in the interpretation of that obligation. In deciding, for example, who should and who should not be the beneficiary of their power to rescue, doctors have no special status because such a decision is a moral and not a medical or clinical one. Of course, medical opinion may well be an important part of the data used to come to a moral decision, just as the opinion of a mine engineer may well be an important part of the data upon which to base a decision as to whether or not to rescue trapped miners. But the decision, although perhaps taken by engineers, will be a moral and not an engineering decision. This point is perhaps worth labouring slightly since doctors are very apt to claim that only they can decide these cases, firstly because such decisions are supposedly 'medical' and secondly because it is they who will have to carry through whatever decision is taken. We have seen that such decisions are not in fact medical decisions in the sense that doctors have any special competence to make them or any right to exclusivity in making them. The second point is even less well taken. It would be like a hangman claiming that it is he who must decide the guilt or innocence of the accused because it is he who will have to carry out the sentence.

There is undoubtedly more to be said here, although I think not a great deal more. In any event we must now turn to the question of what if any exceptions there are to, or constraints there are upon, the very general obligation on us all to rescue those in peril of their lives.

\section{Exceptions}

Given what is at stake, when might anyone at all say 'I don't want to and I don't have to' save the life of another person? Clearly there would have to be something which could plausibly be claimed to be of comparable moral importance at stake or some other equally forceful moral consideration that would show why one shouldn't save (or one should end) this life in these circumstances. The answer would thus seem to be: not unless either-

a) It is probable that I would suffer significant injury (or death) or undergo great hardship in the attempt or as a result of it; or

b) There is something of comparable (or greater) moral importance I must do and I cannot do both; or

c) It would be better for that person if I did not attempt to save him or some other good would be achieved by his death, or by my refraining from saving him, for which end I would be justified in sacrificing his life; or

d) The person does not want to be saved; or

e) The person would be better off dead. 
Conditions ' $c$ ', ' $d$ 'and ' $e$ ' are all exceptions because morality requires, or it is claimed that morality requires, that the person whose life is in the balance be not saved. Or perhaps at its weakest, that there are moral reasons for not saving the victim and we can appreciate that reasonable and humane people would find these reasons compelling. Conditions ' $a$ ' and ' $b$ ', on the other hand, both involve cases in which the potential victim's life should undoubtedly be saved but the potential rescuer believes that there are moral reasons why he or she should not be, or need not be, the rescuer. In these two cases there need be no judgment that it would be better for anyone if the victim were not saved, only that particular people are not required, in these circumstances, to do the saving.

We will take the last three conditions first and look at them just long enough to see the sorts of cases to which they would apply. We will then turn in more detail to the first two conditions because it is these to which doctors must appeal if they are ever to decline to treat the generality of patients.

In what circumstances would condition ' $c$ ' apply? I suppose it would be better for someone if I didn't attempt to save him if either, he would be better off dead (see 'e' below) or the process of saving him would either be so painful and protracted for him that death would be preferable to experiencing it, or his rescue would involve the sacrifice of some other value that $h e$ believed to be more important than his own life, as perhaps is the case when Jehovah's Witnesses require, but refuse, blood transfusions. Where some other good would allegedly be achieved by the death of the person I could save, it must be the sort of scale of good for which I would be justified in sacrificing his life. Some will hold that this could never be the case but I suppose most of us would accept that saving one or more other lives which could only be saved if this person were left to die would be an example. Another might be using the resources required to rescue certain individuals to prevent the certain occurrence of a greater number of deaths from another danger.

How we respond to the request of those under condition ' $d$ ' that they not be saved will depend very much upon whether we judge 'the value of life' to be primarily a value to the person whose life it is or of some independent importance; or perhaps, upon whether we accept that an individual must be free to determine his or her own fate even at the cost of his or her own life. Broadly, those who think suicides should be left alone will accede to such requests and those who think they should be prevented and/or revived will not. The working out of this dilemma is not my present task but at least we can understand someone's finding the fact that a person has sincerely and soberly asked not to be saved, a morally compelling reason for allowing him to die.

Condition ' $e$ ' is both important and problematic. It is important for this discussion because where doctors have judged that it is in their patients' best interests to die they have felt supported in their decisions to let patients die by the belief that they are in any event under no compelling obligation to provide treatment (7). It is problematic because of the difficulty in being satisfied that it is in a patient's best interests to die, particularly when, either through disability or infancy, the patient cannot himself be consulted. Some will claim that we can never come to such a conclusion, others will be able to imagine cases in which they would feel that it would be better for someone not to survive any longer. Where the individual in question is a severely handicapped infant or 'neonate', imagination may be aided by the belief that neonates share something of the moral status of fetuses and are in a sense replaceable. We cannot resolve this very difficult question here and we must simply note that for some people ' $e$ ' will be an empty category and for others not. Either way, given that one form or other of the very general moral requirement is accepted, that we either refrain from decisions the consequence of which is death and other disasters for others or, we act consistently with our belief in the value of life; then unless conditions ' $c$ ', ' $d$ ' and ' $e$ ', apply and the particular individual whose life is at risk is to die, we must save him if we can. Or, we must do so unless conditions ' $a$ ' or ' $b$ ' hold.

\section{What is worth a life?}

Condition 'a' reflects our acceptance of the futility of requiring that people lay down their lives for one another. Equally we recognise that it is unrealistic to expect that anyone will willingly run substantial risk of significant injury or undergo great hardship to rescue others although we may regard a person as a saint or a hero if he does. While it may be hard to specify with any confidence or exactness what is to count as 'significant' or as 'substantial' for these purposes, we do I think, retain a general idea of the sorts of thing that might be proportionate here and this is all we need. For while many would doubt that anyone ought to sacrifice, say, a finger, to save the life of another, most people would accept that working longer hours or taking a (small?) cut in salary would be a price that anyone ought to be prepared to pay to save a life.

Condition ' $b$ ' is similar, and reminds us that life and our commitment to it is so important that we cannot lightly sacrifice the one or turn our backs on the other. What is in fact of moral importance comparable to saving a life may be difficult to specify for all sorts of reasons. There will be those who place an infinite value on life and so deny that there is anything to compare with it in importance. Others will claim that certain values are incommensurable and cannot simply be traded off one against the other. Further difficulties will have to do with the estimation of the probability of various outcomes and other uncertainties, others will turn on the difficulty of weighing the moral importance of various projects or activities. Those who place an infinite value on human life cannot be taken seriously unless they are clear that we should go on saving lives even if the consequences are ruinous for many other aspects of life. And, of course, if such things as housing, education, sanitation and other areas of social wel- 
fare are to be neglected so that resources may be devoted to saving lives, there will inevitably be a delayed feedback effect and the lack of these provisions will begin to cost lives. Those who hold that certain values are incommensurable face a different difficulty. Since deciding what to do is inescapable in a way that deciding what to value is not, they will have to choose to do one thing rather than another while maintaining that this does not commit them to any judgment about the greater absolute value of what they have chosen as compared with the rejected alternatives.

For the other difficulties it is not necessary that we have a comprehensive or even a well worked out system of priorities that we can rank-order with confidence; nor do we need a foolproof method of calculating probabilities or resolving uncertainties, though all or any of these would be useful. However, if anyone is to decline to save the life of another person because there is something else he must do instead, then if he is to retain any moral credit at all he must be able to give a plausible (though not necessarily a decisive) account of how the moral importance of his alternative project compares with that of saving a life. Or, given the probability of saving a particular life that there is a better way to use time or resources. If he maintains that values are incommensurable then he must still justify his choosing to do one thing rather than another.

\section{Sharing the burden}

If we return now to the problem of how these conditions apply to the obligations of medical staff a number of apparently special problems apply. The sorts of cases conjured up by thinking of the obligation as a perfectly general one to save life where we can, tempt us to imagine rather exceptional circumstances in which we find ourselves with the opportunity to save life and readily recognise the lameness of saying 'I can't save that child from drowning I've not finished my tea'. Medical staff are presented with life-saving opportunities rather more often than most of us imagine that we are. These apparently special problems are all to do with how burdensome a business life-saving is, or might be, for particular individuals. I say they are apparently special because we all of us have more of such opportunities and therefore more of a burden than we imagine (3), but I will concentrate just on the case of doctors and on how the burden which falls on them is to be shared between them and the members of the society of which they are a part.

Let's suppose that the last doctor happens to be the only doctor, because say, she is first on the scene of a huge disaster and no help can be expected for a long while. In those circumstances so long as her skills are essential to life it is clearly her moral obligation to provide them. She cannot insist on normal office hours, or that she is in vacation time or that she has decided as of now to give up medicine for a career in television. But this seems reasonable only in an emergency. The burden of such unremitting life-saving might be too great to bear on a long-term basis, at least if all the burden fell on one individual.

Suppose a particular doctor always found herself as the last doctor because her colleagues played elaborate games of 'pass the patient' and consistently cheated so that when the music stopped she was always left holding the baby. We would think it unjust that this doctor must devote twenty-four hours a day to caring for the sick when her colleagues merely shared the burden of minding the gramophone. But here our judgment would not be that there was no obligation, rather that the obligation should be fairly distributed. So that although, with exceptions already noted, the last doctor is obliged to treat her patients rather than let them die, there is also an obligation on the rest of us to see to it that the burden (even if it isn't a burden?) of being the last doctor is shared equally or at least fairly.

\section{Scarcity of doctors}

More common than being the only available doctor will be the situation of doctors in a society which has insufficient doctors. We would say, I think, that a society is short of doctors when - if the burden of treating those who need care were to be spread fairly through the population of practising doctors - a doctor could not, under those circumstances, discharge her obligation to the sick or dying without either working significantly harder than people in that society normally work or without hardship to herself. A society will thus be short of doctors in this sense even where perhaps some doctors are unemployed or otherwise present but unable to practise. Well, where doctors are in short supply they will clearly have a hard time of it if they are to rescue all those who need to be and could be saved. But unless this hard time is so hard as to bring it under condition ' $a$ ' then their obligation to save life remains. But we must remember that this obligation falls equally on anyone and everyone who could help, and while it may be that only medically qualified people can help those in immediate danger there is something that the rest of us can do to help as well. We can provide the resources that will remove the scarcity of doctors (8). Unless we are willing to work at least as hard as the doctors to remove the shortage, then we can hardly complain if they are unwilling to fulfill their obligations to the dying. Of course, if we work harder then doctors will have to work harder as well, until rough equilibrium is reached.

\section{Comparative judgments}

It is important here to keep clear the distinction between judging people and judging actions or between assigning blame and assigning responsibility. Because doctors are no more obliged to rescue the dying than any other members of society, their complaint (or anyone's) against a society that allows there to be a shortage of doctors, is at least as great as the complaint of any member of that society against the doctors for failing to do more than others are doing to save the 
dying. So that while the obligation of doctors to rescue those they can rescue is not lessened by the burden of the task (unless that burden amounts to grave hardship) it would be wrong to think that doctors are morally worse for not working much harder as a matter of course than other members of the society.

And of course, where doctors are not in short supply they seem clearly obliged to help the dying unless conditions ' $a$ ' to 'e' apply, even if this involves occasional emergencies where much harder work than normal is required.

We have concentrated on saving life as the clearest and most important obligation to our fellows. Whether the same arguments can be applied to the general question of the obligation to provide all the various things that count as medical care is less clear. It may well be that we could make rough but workable judgments as to the importance of each sort of treatment, and 'pro rata' judgments about the importance of alternative projects that those who could provide the care might wish to undertake. Many injuries, illnesses and conditions which are not lethal may, to those who suffer from them, be a fate almost as bad as death (and perhaps sometimes worse). Here the obligation to cure or heal if possible and to relieve terrible pain may be clearly as important as saving life or postponing death. In other cases day to day medical care may be a fairly low personal and social priority, and the obligation to provide it weak or even non-existent. Of course, it may sometimes (or always?) be necessary to see patients to decide which is which, and the obligation to assess may be much more comprehensive than the general obligation to treat. How all these problems are to be resolved will require much more detailed study than can be given here.

We should note finally that special difficulties will arise when a particular society, community or state cannot afford all the doctors (let alone all the other medical resources) it needs, however hard the people work. Such a society will effectively be a permanent disaster area and what morality requires of doctors or anyone else in such circumstances may be a problem of a different order. We should note, however, that the same general moral principles that require us to save the lives of our fellows if we can, are not parochial and do require us to work to save lives in that society as well as in our own. I do not know whether adequate principles for distributing the burden of life-saving and other health care would reveal the whole world to be a disaster area or not. But the obligation to share this burden fairly does not wait upon our knowing how great a burden it is.

\section{References and notes}

(1) Anscombe G E M. Commentary 2. Fournal of medical ethics 1981; 7: 122-123.

(2) For economy I will usually use the word 'doctor' to cover medical staff more generally.

(3) A more lengthy defence of this idea can be found in Harris J. Violence and responsibility. London: Routledge \&
Kegan Paul, 1980 and in Harris J. Bad Samaritans cause harm. The philosophical quarterly 1982; 32, 126. The contrary view is defended inter alia by Mack E. Bad Samaritanism and the causation of harm. Philosophy $\mathcal{E}$ public affairs 1980; 9, 3: and James S. The duty to relieve suffering. Ethics. October, 1982.

(4) And, of course, our decision may equally well be one not to provide life-saving resources: 'Funds for kidney units are running seriously short. About half the 2,200 people whose kidneys fail, die because there are no facilities to save them, Professor Cyril Chantler of Guy's Hospital said yesterday.' Reported in The Guardian 1982 Jan 15.

(5) Of course, a life may be valuable even when it is of no value to its 'owner' but I shall assume what will be controversial for some, that we ought to accept an agent's own assessment of the value of his or her life and so it will cease to be better to postpone death for someone when he himself ceases to believe it to be better.

(6) Professional killers, so called 'hit men', would be an example of the opposite.

(7) This belief supports the widespread practice whereby doctors mark some patients for resuscitation and not others, should the patients suffer 'cardiac arrest' while in hospital. The same belief supports the equally widespread practice of allowing geriatric patients to die when their lives could be further prolonged. The moral grounds for such decisions need to be much more clearly articulated than they have been.

(8) And, of course, other rescue and life-saving equipment and personnel.

\section{Commentary}

John A Davis, University of Cambridge Clinical School, Cambridge

John Harris, in his paper 'Must doctors save their patients?', poses a number of questions in relation both to ethics in general and medical practice in particular which perhaps need other answers than those which he tentatively arrives at. It has been said that the ethical dilemmas that have arisen as a result of advances in medical technology, and which call for a new casuistry if not new principles, have saved moral philosophy as a subject from running into the sands of triviality; and, certainly, I for one believe that reflection on medical practice has more to offer moral philosophy than the latter has, in the way of guidance, to working doctors: in fact I believe that philosophy is essentially reflective and that the claim of morality to be prescriptive needs examination - such as that provided by Professor Hare, in which he separates fundamentals from working rules and intuitive reactions.

But to return to John Harris's thesis, which is, if I understand it rightly, that there is no essential difference between the moral duty of all of us to come to the aid of fellow beings in distress and that of the physician to make his skills available both at large and at the bedside: I agree with Harris that when, for instance, a fel-

\section{Key words}

Doctor-patient relationship; duties; medical ethics. 
low guest collapses at a dinner party, the only reason for asking if there is a doctor in the house is because he is more likely to be able to offer effective help than the rest of the company; but if, to use another example, a female guest were to go into labour and a midwife were present, she would take over by common consent; and if the problem were a hold-up, we would reasonably defer to a policeman if he were one of the diners. I would distinguish this kind of first aid quite sharply from what a doctor does for one of his accredited patients to whom it is his duty to offer more than first aid in the light of a much greater and privileged knowledge of all the circumstances and of the place of the illness in his patient's life history. The obligation here is essentially contractual and involves the physician, in accordance with Hippocratic tradition, putting his patient's 'good' before his own in the context of the consultation - though clearly overall his liability is limited in the sense that it does not involve, for instance, providing food and shelter or even drugs other than by prescription. Since the relationship is essentially contractual, even if the contract is made via a third party such as a National Health Service authority, the doctor can morally refuse to enter into it (though this might mean resigning from his post); and the patient also is, of course, entitled to break it off. Within this arrangement a physician will do what he can to make his patient's life more worth living; and this obviously does not oblige him to give overriding importance to its prolongation; quality, not quantity, being the objective. The physician in essence comes into a novel in which the patient is narrator and attempts to occupy an honourable and appropriate role in it as might be judged by a disinterested reader. There are problems when the client and the patient are not the same person, which I have examined in another context (1) but they are not insuperable. As regards the question of whether a physician is entitled to refuse taking on a patient who needs his care and perhaps cannot find another doctor: it is surely only reasonable for him not to enter into a contract which he has not got the resources to honour except by dishonouring another contract with someone whose claim is prior. But it would be only decent to render whatever first aid might appear to be needed and at least to attempt to direct the disappointed patient elsewhere. This is not, in fact, a situation that very often arises, even in countries where physicians are thin on the ground; mostly we manage as best we can and do what we have to do; but the decision is ours and no one, moral philosopher or bureaucrat, has the right to impose on us. Nor is it something that patients themselves seem to expect. All this fits reasonably well into a morality based on 'do as you would be done by' in the subtlest sense; and, of course, by taking up medicine as a career, physicians in a sense abjure fatalism and commit themselves to making the best of things in the here and now, whatever their eschatology. I should add that by joining a profession with moral traditions of its own, doctors often find themselves living up to higher standards than they would otherwise profess to observe, just as more courage is expected of professional soldiers than we ask of ourselves in civilian life. In this respect we ask more of ourselves than ordinary morality would have the right to exact; and it is for this reason that the public rightly prefers, on the whole, to consult members of the medical profession rather than mountebanks about their bodily ills. But this raises other issues to which perhaps John Harris will address himself if this debate continues.

\section{References}

(1) Davis J. Presidential address to the paediatric section of the Royal Society of Medicine, October, 1982. Fournal of the Royal Society of Medicine. In press.

\section{News and notes Symposium about sex}

The Liverpool Medical Group are holding a one-day symposium About sex on March 10 next year. The morning session will concentrate on problems as perceived by the individual and the afternoon session will focus on sexual problems and society.

Topics will include: Sexual problems of the handicapped and infirm; Sex, education and the adolescent; Sex in conflict with the law; Problems of sexual offenders; and Prostitution.

The symposium will be held in the Cohen lecture theatre, the Duncan Building, Royal Liverpool Hospital, Daulby Street, Liverpool and will begin at 9.30 am with registration and coffee. Cost is $£ 3.00$, but there is a reduced fee of $£ 1.00$ for the "unwaged".

If you want to attend write to: The Secretary, the Liverpool Medical Group, PO Box 147, Liverpool L69 3BX. 